\title{
Influencing community mindsets: the role of outreach programs in achieving urban sustainability
}

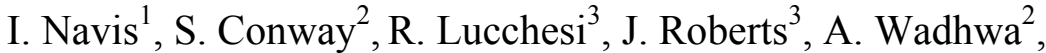 \\ P. Washeba ${ }^{2} \&$ R. Cameron ${ }^{2}$ \\ ${ }^{1}$ Clark County, Nevada, USA \\ ${ }^{2}$ Urban Environmental Research, LLC, USA \\ ${ }^{3}$ Lucchesi Galati Architects Inc, USA
}

\begin{abstract}
Las Vegas, Nevada, is an emerging leader in urban sustainability. A large component of bringing change at a metropolitan scale comes from targeting behavioral changes through community education. This paper presents two such initiatives for mass outreach being employed in the Las Vegas valley. While completely distinct from each other in their delivery methods, these initiatives explore local technologies and region-specific information disseminated to the public as a means for enabling action.

The Las Vegas Springs Preserve (the Preserve) is a 180-acre cultural institution in the heart of the valley, which provides guidance and vision for sustainable living to the community. Using it as an example, a discourse is offered about what sustainable tourism means in the peculiar setting of Las Vegas, where tourism has historically been the primary driver in shaping local culture. The very inception of modern-day Las Vegas can be accounted to the onset of gaming that forms the backbone of the tourist industry. Unlike other tourist-driven economies where tourism is typically driven by the unique history, culture or natural resources offered by the place, the history of tourism in Las Vegas $i s$ the history of Las Vegas. Thus, 'sustaining' tourism so as not to harm the culture that is defined by it then becomes a self-closing loop. In such a setting, tools designed to bring behavioral shifts are posited as purposeful agents of change and become the overarching connectors leading to inter-sectoral dialogue, influence urban policy, and create a positive 'feed' into the existing culture; an inside-out transformation. This paper explains the architectural
\end{abstract}


program, design concepts and exhibits within the preserve in the above-stated context. Facilitated by the Las Vegas Valley Water District, the Preserve is a proving ground for reinforcing the inter-connectivity of living systems and the interaction of social, environmental and economic sustainability.

The regional carbon management tool is discussed as another such initiative that brings together policy makers and citizens on a common platform enabled by region-specific information and GIS technology.

Keywords: community involvement, mass outreach, tourist-driven economy, living systems, local technologies, sustainable tourism, behavioral changes, community education, carbon counting, GIS technology, energy use, housing stock, carbon coefficient.

\section{Background and introduction}

\subsection{History of Las Vegas}

While the area surrounding Southern Nevada, where Las Vegas lies, carried no intrinsic worth as an agricultural resource, it offered two precious resources to early explorers: mineral deposits (especially gold) and water from the artesian wells. The region was initially discovered by early Spanish explorers as a source for abundant spring water that shortened the Spanish Trail from the East coast to Los Angeles by many days, easing rigors for the traders who used the route [1]. In the 1850s, Mormons from Utah established the city of San Bernardino at the east end of the Los Angeles basin and put in a settlement at Las Vegas as a general provisions site [2]. The 1860s gold strike further expanded the region's role for catering to the needs of the prospectors. With the expansion of the railroad in the early 20th century by William Clark, the townsite officially became the city of Las Vegas on May 15, 1905 [3]. In that sense, Las Vegas has always been a service-based economy, a course that post-modern cities followed well after World War II and the age of mass production and manufacturing had passed. With the commissioning of the Boulder (now Hoover) dam in 1928, the population of Clark County nearly doubled due to the creation of new jobs at a time when the rest of the nation was going through the Depression. Downtown warehouses and railroad shipment facilities expanded, even as the dam itself became a major tourist attraction. By the late 1930s, more than a quarter of a million tourists visited Las Vegas and spurred the growth of the hotel and casino industry [3].

Gottdeiner et al. [3] posit the great risks that have always been part of the equation in southwestern development and how Las Vegas has been typical of this boom and bust cycle (pp. 4). On one hand, one may see the region to stand in the exact same condition of boom and bust, given the recent economic recession and how the region experienced some of the worst real estate slumps in the nation and higher than national average numbers for unemployment. In the last three years, population projections that had been consistently used over the last decade and related forecasts have come tumbling down as the influx of tourists declined and driver's license surrenders went up as residents moved to 
other cities in search of jobs. On the other hand, Las Vegas may be explained though Lefebvre's socio-spatial theory that posits investment activity in the built environment as a combination of actors and structural conduits, business interests, public and private investors, and homeowners: "a complex shifting process of conflicting interests devoted to the accumulation of capital and the protection of the quality of life" [3]. It is this latter part, the protection of the quality of life, that efforts like the Las Vegas Springs Preserve endeavor to achieve.

\subsection{Existence of cultural dichotomies in Las Vegas}

At a recent Las Vegas annual business convention focusing on 2010 regional economic and cultural forecasts, the President and CEO of the Las Vegas Convention and Visitors Authority played some of the upcoming ad campaigns for Las Vegas ready for broadcast across the nation. With the recovering national economy, the campaigns attempt to revive the famous 'What happens in Vegas stays in Vegas' theme, with the central focus on the Las Vegas Strip, the casino and gambling circuit, and the other industries developed directly as a result of it: a consciously cultivated image of extravaganza and excessive indulgence that has been carefully shaped and maintained over the years ever since Las Vegas positioned itself as a gaming hub in the early 1940s. This now well-established identity of "Vegas" is so strong and monolithic that it suppresses the emergence of other less powerful cultural signifiers that could contribute to the region's overall image. What is no longer talked about is the pre-World War Las Vegas, the significance of its geographic location, ecology and natural resources that attracted the early explorers.

Another significant factor in shaping the local culture is the fact that given its rather short and sudden growth over the last half of the century, majority of Las Vegas residents are from other parts of the country. In 2000, a local TV channel, KLAS TV, ran a campaign called the 'My Hometown' campaign. Under the campaign, booths were set up at various community events occurring throughout the year and participants would be selected randomly from the crowd. When asked where they were from, most people, irrespective of how long they had lived in Las Vegas, would state their original town as where they belonged. The purpose of the campaign was to instill a sense of community amongst the residents and encourage them to think of Las Vegas as their home. Although inconclusive, such campaigns provide evidence of a missing sense of place in the larger Las Vegas community, which exists outside of the tourist culture. Situating projects like the Las Vegas Springs Preserve in such a cultural setting thus takes on a new meaning. The built environment created also fulfills the niche' of meaningful places for the community to identify with and 'own'.

\section{The Las Vegas springs preserve: community education and beyond}

The Las Vegas Springs Preserve (the Preserve) [4] comprises of 180 acres of desert land in the heart of the valley providing home to several major institutions 
positioned to engage visitors with the valley's history and natural resources. The \$250 million facility was financed by the Las Vegas Valley Water District with the primary objective of promoting water conservation and educating the community about tools and resources available to achieve this. However, during the visioning and conceptualization process, it was soon realized that water conservation not only goes hand-in-hand with holistic living principles, but also is to a large extent dependent on the overall individual mindset, awareness and attitude towards sustainable living. Being situated at the very site of the first artesian springs that brought the early Spanish explorers to the region, the program naturally progressed towards showcasing the natural resources, geologic and cultural history of the valley as a part of this education. The idea that the Las Vegas valley needs to be looked at as more than just a capitalist venture, an investor's paradise, or a 'job market' but instead as a finite resource comprised of delicate living systems could thus be introduced. Region-specific education was also taken further when other regional agencies saw the Preserve as an opportunity to spread awareness about local issues such as flash floods. Figure 1 provides a general map of the Springs Preserve, the surrounding greens, trails, artesian springs and the housed facilities (inset). Hiking trails take visitors though Las Vegas at its most natural state, when it was the original, neon-less desert oasis, even as the glittery Las Vegas strip skyline stands in the background, no more than a few miles from the Preserve.

\subsection{Springs preserve background}

Water has always been a fundamental consideration in the Las Vegas Valley. Humans have used the Preserve as a crossroad through the desert Southwest since the Pleistocene Age thanks to its abundance of water. The site has hosted three known Native American cultures: the Puebloan, Patayan and Southern Pauite. Early Spanish explorers named the area "Las Vegas", the Spanish word for the meadows that were found on this site. Travelers on the Spanish and Mormon Trails, and later settlers, ranchers, early Las Vegas residents and railroad employees, relied on the Springs and its tributary Las Vegas Creek as their source of life.

A wide variety of wildlife species also make their home on the Springs Preserve site, due in part to the relative isolation (it is surrounded by development), its size and vegetation communities. Cottonwood, willow, and mesquite bosque provide food and shelter for the 150 different species observed over the past five years.

The project site contains a 10,000 year old physical record of the biological, geological and cultural history of the Las Vegas Valley and was listed on the National Register of Historic Places in 1978. Today the Springs Preserve is owned and operated by the Las Vegas Valley Water District as an active water resources management facility, which is a critical link in the delivery of potable water to much of the metropolitan area. Preservation and management of the special natural and historical resources located within the Preserve and the employment of industrial facilities to further the District's water conservation 


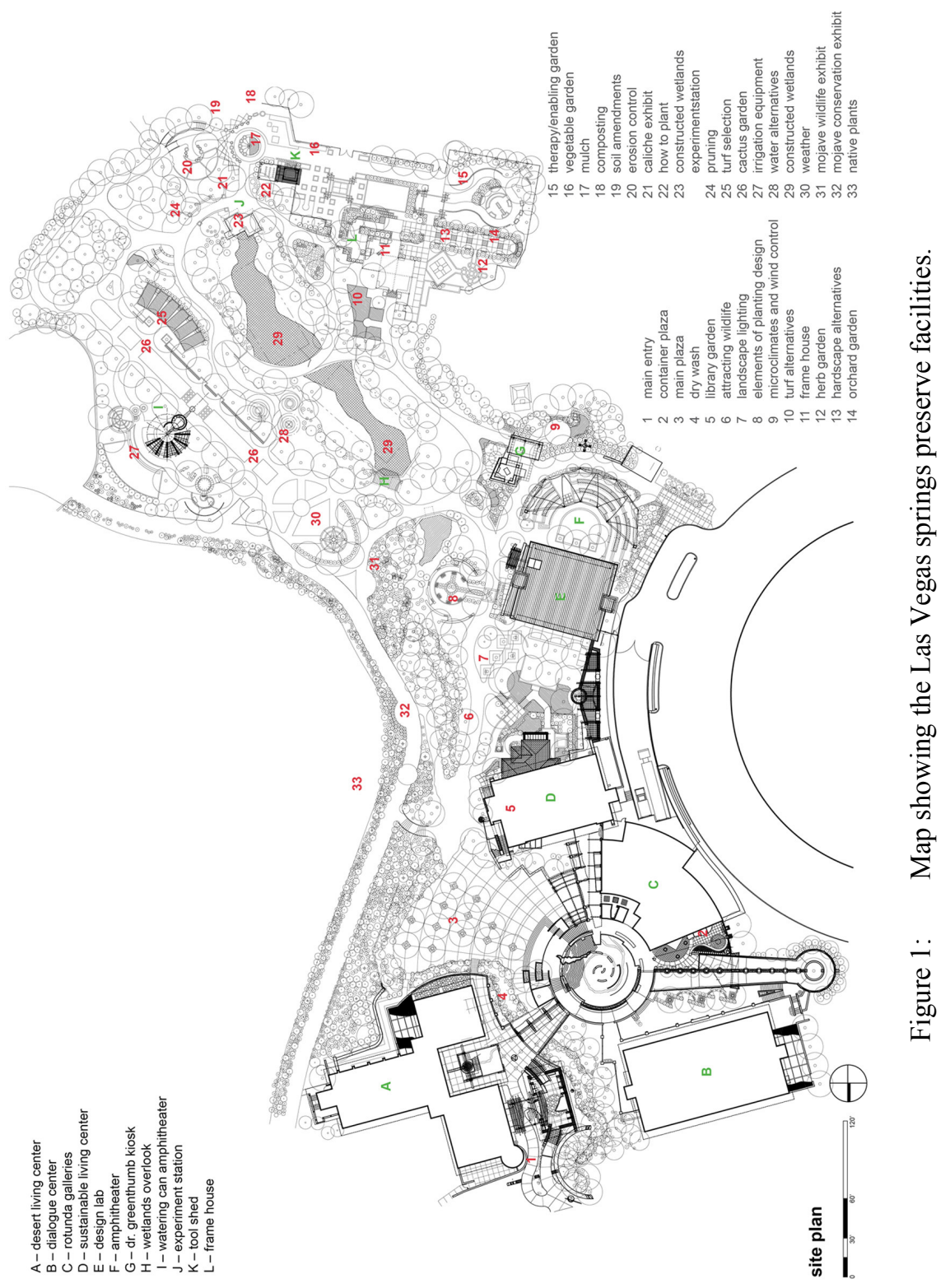


and sustainable education efforts presented a unique opportunity for the community. Toward that end, the Las Vegas Valley Water District partnered with Springs Preserve Board of Trustees and Foundation to realize the design and construction of this effort targeted towards community education.

\subsection{The Desert Living Center (DLC)}

The Desert Living Center (DLC) is an action-based public outreach and applied research facility that serves as a catalyst for individual and community change from being "in the desert" to being "of the desert." It comprises of a complex of five LEED-rated buildings (LEED stands for Leadership in Energy and Environmental Design and is an independent rating system developed by the United States Green Building Council that provides standards for developing and benchmarking environmentally conscious building design). Exhibits illustrate benefits of recycling, conservation and alternative energy sources through an interactive environment of galleries, design labs and training centers where the architecture and construction techniques of the buildings also double up as a learning platform. The interpretive educational story lines are carried throughout the facility with items ranging from the forty three hands-on interactive environmental exhibits, twenty static sustainable design principles exhibits integrated into the buildings, two temporary galleries, four classrooms, a dialogue center, library/research center, design lab and a technical training studio.

\subsubsection{DLC strategies and results}

Starting from the conceptual design itself, DLC is designed to reflect alignment with the local environment, beginning with solar orientation to optimize the benefits of the sun as a lighting and heating source. It continues underground by utilizing the earth as a thermal insulator for the structures by integrating the buildings into the land and then carries above ground where the mass and thickness of walls assist in protecting heat gain and loss. Thermal mass is achieved through the use of rammed earth and cast-in-place concrete construction. Additionally, through the use of straw bale construction, the buildings are able to achieve very high insulation values, which protect the inside environment from the intense Las Vegas heat. The long roof overhangs protect the buildings from summer heat gain while allowing the low sun of winter to warm the interior spaces. Cool towers and courtyard designs are intrinsic to reducing heating and cooling loads. Technologies for the Desert Living Center are incorporated throughout the facility, but are not a primary focus in the design. Due to the rapid change of technological advances, a product that may be cutting-edge today could be outdated in two years. The technologies that are used work as a compliment to the basic sustainable design principles. These include automated window openers to take advantage of natural ventilation, advanced cooling strategies, radiant floor heating systems, light photocell sensors, solar hot water heaters, and reclaimed water systems. Visitors are educated about these architectural elements during tours of the facility. Additionally, the accompanying five-acre conservation gardens demonstrate 
desert-appropriate water and energy-conserving design solutions, planting design, landscape lighting, and "how to" areas for irrigation and planting. Garden exhibits are also used to further Mojave education, as are the constructed wetlands for treatment of all gray and black water for the entire Preserve site, and is reused in the DLC toilets and gardens- another example of how functional elements of the facility are also used for education and awareness. The estimated annual energy savings for the DLC alone approximate about 279,591 kWh, avoiding 258 tons of carbon emissions annually. Water savings are estimated at 380,099 gallons per year and about 7748 tons of waste has been diverted from landfills.

\subsection{OriGen experience}

As the interpretive focal point for history at the Springs Preserve, the 97,000 square foot 'ORIGEN Experience' is comprised of three galleries featuring over 75 permanent exhibits, an indoor theater and traveling exhibit space. Itself a part of the Visitor Center, it houses the Big Spring Gallery and Theatre, live animal habitats, natural Mojave gallery and the New Frontier gallery. The Big Spring Gallery showcases the work of local artists and exhibitions that have context to the Preserve's mission. Educational films introduce visitors to the natural history of the region, explaining the location of Las Vegas, and take an in-depth look at the importance of water in its development.

\subsection{Nevada state museum}

Currently unopened and awaiting further funding, the Nevada State Museum and Historical Society will feature exhibits to advance the understanding of the

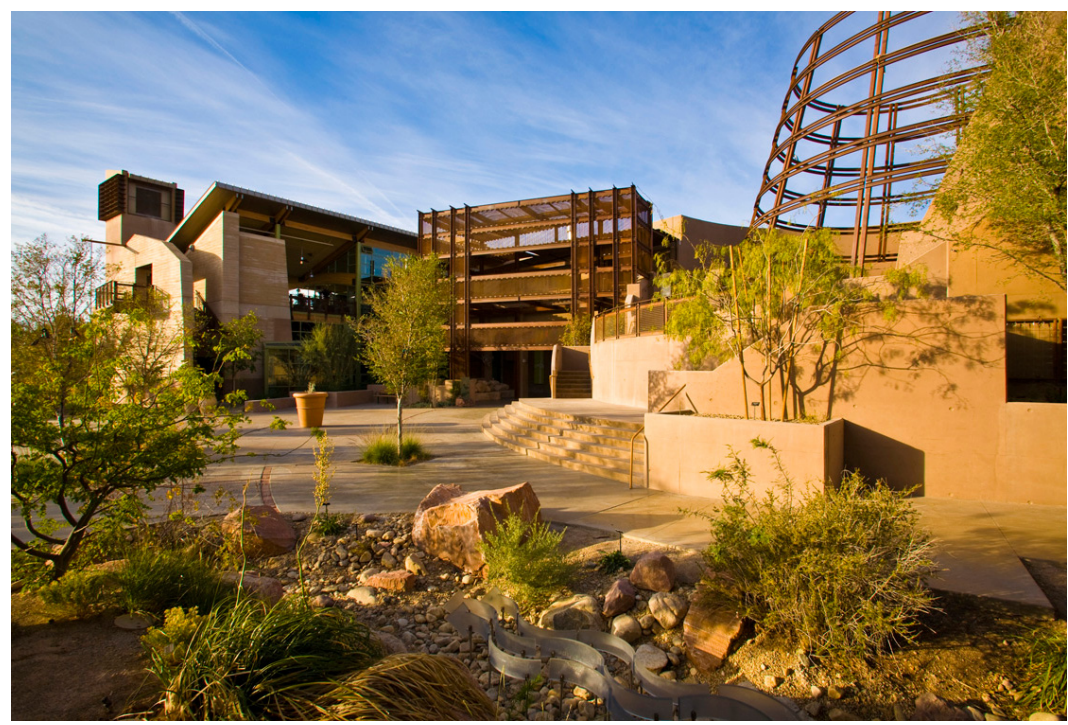

Figure 2. 
history, pre-history and natural history of Nevada, emphasizing Southern Nevada and its relationship with surrounding areas, as well as new exhibits that will shed light on the study of how dinosaurs lived in Southern Nevada millions of years ago.

\section{Residential carbon emissions mapping tool}

Another initiative that is under-development in the Las Vegas Valley is a regionspecific carbon emissions mapping tool [5] that accurately baselines residential energy use per street and provides a comprehensive picture of local hotspots. The tool utilizes valley wide databases of energy consumption, taking a single dwelling unit as its smallest unit of measurement. Thus, a bottom-up inventory of resultant carbon emissions is created. Using web-enabled Geographic Information Systems (GIS) functionality, the tool further lends itself to mass outreach programs where consumers are able to compare their individual carbon footprint to neighborhood, city, state and national averages. This is anticipated to instigate a behavioral change amongst consumers by providing them specific information on the effects of their individual energy use on the environment. A sample snapshot of one of the tool's outputs is given below. The map legend is designed to delineate local, state and national averages of electricity usage and generated carbon dioxide emissions.

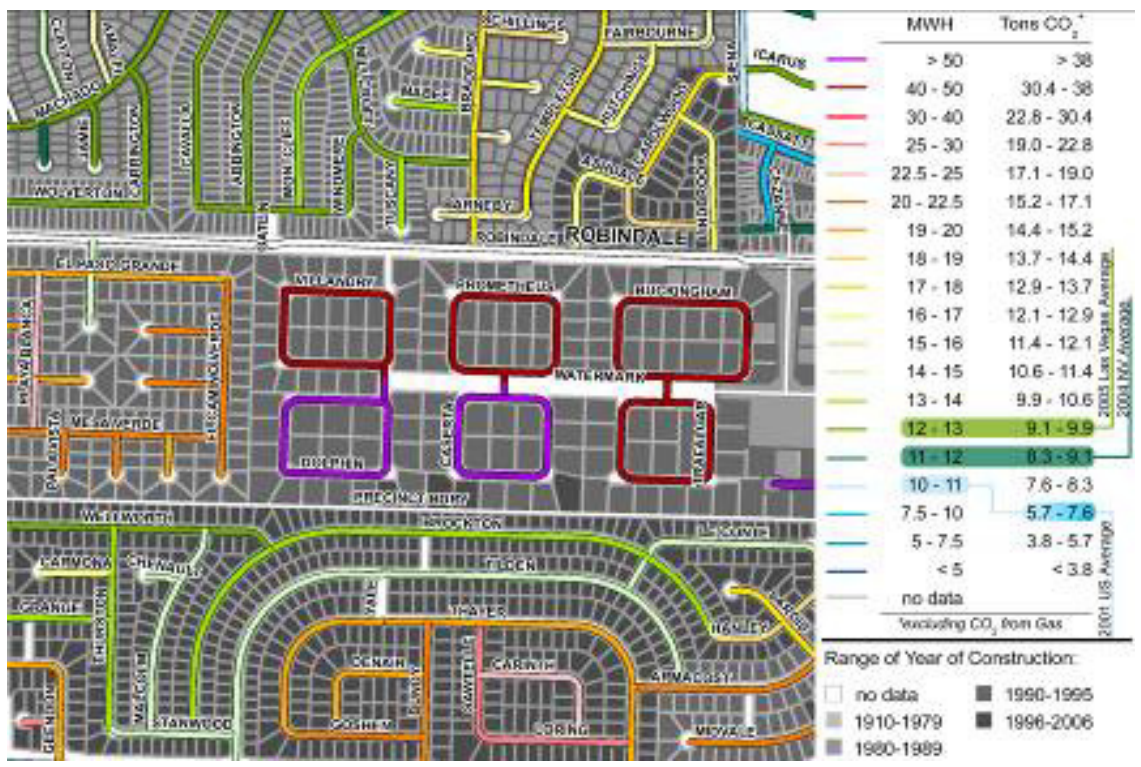

Figure 3. 


\section{Lessons learned and conclusion}

If one is to define the sociological notion of place, which is intangible and comes from a sense of belonging to a community, the Las Vegas region consists of two such 'places'. The tourist's 'Vegas' remains distinct from Las Vegas the local community of workers, families and life outside the Las Vegas Strip.

The Las Vegas Springs Preserve opened in June 2007. The expected visitor volume to the Preserve at the time of its design was about 600,000 visitors per year, about $1.5 \%$ of the total visitor volume to Las Vegas [6]. Today, the average annual visitor volume to the Preserve is about 210,000 [7]. While the facility brings in about $99 \%$ of its expected local visitor volume, the tourist community still remains a challenge, and further highlights the disconnection between Las Vegas and "Vegas". The Preserve continues to act as a bridging ground for this disconnect as it gains its own foothold and popularity as a nationally recognized symbol of sustainable design.

\section{References}

[1] Las Vegas Review Journal. “Las Vegas History Outlined.” July $20^{\text {th }}, 1989$.

[2] Moehring, E.P. Resort City in the Sun Belt: Las Vegas 1930-1970. Reno/ Las Vegas: University of Nevada Press. 1989. pp 2.

[3] Gottdeiner, M., Collins C., and Dickens, David. Las Vegas: The Social Production of an All-American City. Blackwell Publishers. 1999.

[4] The Las Vegas Springs Preserve. Principal Architects: Lucchesi Galati Architects, Inc. All drawings and text related to the Springs Preserve provided by Lucchesi Galati Architects, Las Vegas, Nevada, USA.

[5] Wadhwa, A. Baselining Carbon Dioxide Emissions of the Las Vegas Metropolitan Area Residential Building Sector. Master's Thesis. University of Nevada Las Vegas. 2007.

[6] Las Vegas Convention and Visitors Authority. 2010.

[7] The Las Vegas Springs Preserve. Marketing Department. Personal Communication. Ms Dawn Baraclough. Mar 2010. 